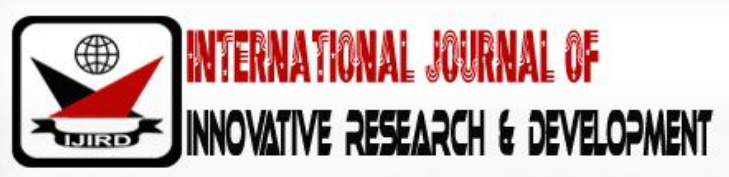

ISSN 2278 - 0211 (Online)

\section{Conversion of Polytechnics to Technical Universities (TUs): Challenges in Administrative Records Management in TUs in Ghana}

\begin{tabular}{|c|}
\hline Akwasi Duffour Frimpong \\
Assistant Librarian, Kumasi Technical University, Ghana \\
Baffour Ohene Agyekum \\
Assistant Librarian, Kumasi Technical University, Ghana \\
Hagar Amponsah Asare \\
Assistant Registrar, Kumasi Technical University, Ghana
\end{tabular}

\section{Abstract:}

A quantitative study of 5 purposively selected Technical Universities (TUs) of Ghana was conducted to assess the administrative records management after the conversion of Polytechnics to TUs. The descriptive research design was the strategy employed. The stratified and simple random techniques were used to sample 50 respondents from these TUs. Findings of the study showed among other things that, before the conversion from Polytechnic status, concentrations of administrative records management were on policies and procedures for the creation and storage of records in both electronic and paper format and least concentration on organizational file plan that compile primary types of functional Units in order to locate information. After the conversion to TUs, there was a remarkable improvement on policies and procedures used in the creation and storage of administrative records in manual format and organizational file plan that compile primary types by functional Units in order to locate information. Therefore, it was recommended among others that TUs should include administrative records management in their strategic plan to allocate the necessary resource for its effective and efficient management.

Keywords: Administrative records, records management, records keeping, technical universities, Ghana

\section{Introduction}

Throughout the world, all organizations, whether small or large, public or private, have one thing in common, each produces records in carrying out their daily activities. Information created, received and maintained as evidence and information by an organization or person, in pursuance of legal obligations or in the transaction of business BS ISO 15489, (2000). Records management is the process of managing information resources that can be reproduced in the conduct of business activity. It was again defined as the field of management responsible for the efficient and systematic control of the creation, receipt, maintenance use and disposition of records ISO, 15489(2001).

A lot of individuals have the impression that records management is just about hoarding everything that comes into one's department in the course of doing business. Shepherd (2006) stated that organizations use records to show their compliance with the best standards of practice and recognized policies. Citizens right such as entitlement rights, legal rights, security rights, financial rights and much more are ensured when records are well managed.

Dzandu, (2009) posits that without proper management of records, rule of law, management of state resource, probity, accountability, foreign relations and protection of entitlements and right of citizens would be meaningless. In a related development, Duose (2009) indicated that when records are properly kept by public officials, they can rely on it whenever the need arises. Ngoepe (2004) indicated that a sound records management is the foundation of any higher educational institution to provide the needed services, to fulfil its obligation of accountability towards the immediate community, students and staff and protection of their rights. TUs (Polytechnics) in Ghana as reputable higher educational institutions apart from the Traditional Universities play a significant developmental role in Ghana by churning out middle-level labour force for all sector of the economy. Therefore, there is the need for accurate management of administrative records within these tertiary institutions. 


\subsection{Overview of TU's in Ghana}

The government of Ghana in 2016, converted 8 Polytechnics in Ghana to TUs (TUs) with a redefined mandate to provide higher education in engineering, science and technology-based disciplines, technical and vocational education and training, applied arts and related disciplines with little concentration on Business and Humanities. This is clearly stated in the TUs Act, 2016 (Act 992) passed by the Parliament of the Republic of Ghana and assented to by the President of Ghana on 31stAugust 2016. Thus, TUs are technological universities with a focus on the application of technology to the various fields of learning rather than the search for new knowledge. They are mandated to offer a minimum of a four (4) year Bachelor of Technology (B Tech) degree programmes in Science and Technology- based disciplines. The new converted TUs are Kumasi Technical University, Accra Technical University, Sunyani Technical University, Koforidua Technical University, Ho Technical University, Tamale Technical University, Takoradi Technical University and Cape Coast Technical University (MOE, 2014)

\subsection{Problem Statement}

Bailey et al. (2011) indicated that in Ghana, the problem of proper records keeping becomes a challenge for most tertiary institutions by allocating larger office space for the storage of students and administrative files manually.

In recent times TUs in Ghana have faced a lot of challenges prior to the conversion of Polytechnics to TUs with which administrative records management played a major part MOE (2014).

Requirements for the conversion among others included evidence of Memorandum of Understanding (MoU's) with collaborating industry partners, personnel records, financial reports, the curriculum of courses, the establishment of Faculties, existing policies, reports etc. It was observed that information or records were not regarded as an important resource that may influence the conversion of the Polytechnics into TUs until the process began.

This observation has prompted the interest of the researchers to undertake their study, which seeks to create and enhance the awareness and sensitize Technical University's staff of the fundamental role played by proper keeping of administrative records in fulfilling its new mandate.

\subsection{Objectives}

The main objective of the study is to bring to the fore the role of administrative records management in TUs in Ghana in fulfilling its mandate. Specifically, the study attempts to:

- Assess the administrative records management practice in TUs in Ghana.

- Identify the positive effects derived from proper administrative records management in TUs in Ghana

- Examine problems confronting administrative records management by TUs in Ghana.

- Explore appropriate remedial strategies being taken by the TUs in Ghana.

\subsubsection{Research Question}

- What are the administrative records management practices in TUs in Ghana?

- What are the positive effects derived from proper administrative records management in TUs in Ghana

- What problems, if any, are faced by TUs in Ghana on administrative records management?

- What are the efforts being made to improve administrative records management in TUs in Ghana?

\section{Literature Review}

\subsection{The Concept of Administrative Records Management}

McKemmish (2001) defines record management as the process that captures, maintains an accurate, complete, dependable and usable documentation of activities of an institution in order to ensure legal compliance, evidential, accountable and social requirements.

A record had been defined by ISO 15489 as information created, received and maintained as evidence and information by organization or person in pursuance of legal obligations or in the transaction of business. Kenosi and Moswen (2018) defines records as "definition stored information, regardless of media or characteristics, made or received by an organization that evidence of its operations and has value requiring its retention for a specific period of time"

A record is defined based on the format it comes with physical/ manual or based on the content of the information. It has been explained as an extension of human memory, purposefully created to record information, document transactions, communicate taught, substantiate claims, advance explanations, offer justification and provide lasting evidence of events (Cox, 2001)

Institutions and individuals create records in a variety of media and formats. It is quite common for records relevant to a single matter to exist partly in a paper file, partly in an email box and partly in a spreadsheet application or in a relational database (Duranti, 2010). Administrative records are created to support the activities that are carried out within an organization. They ensure efficiency and effectiveness in the day-to-day administration of a business entity. Management of administrative records is the orderly control of all forms of records either in the digital/soft or manual/print from their creation to their final disposition. This includes the development and application of standards for the creation, use, storage, retrieval, disposal and archival presentation of recorded information (Brooks, 2007). 
Dzandu (2009) stated that for good governance, records are created to ensure that there is a rule of law, management of state resources, probity, accountability, foreign relations and rights of the citizens are protected.

Further to the above statement, Duose (2009) indicated that records serve as evidence of transactions/ dealings by public officers if they are properly kept. Administrative records, therefore, are the pivot around which an organization revolves around its day-to-day activities.

\subsection{Records Management in Tertiary Institutions}

Records management programmes work within the stated structure of policies, rules and procedures that gives guidance to practice. The reason of these is to ensure that a conducive environment is provided for proper records management (Ngulube, 2005). This is particularly important in an environment such as the TUs in Ghana where the duty of records management is shared among the various departments with little or no centralized control. A suggestion by Mnjama (2002) indicates that the evidence of neglect of records management in universities is the lack of coordinated and planned programmes within these institutions as well as an absence of policies, procedures and facilities for managing records. According to Azameti and Adjei (2013), per the isomorphism principle, instituting internal policies to manage academic records implies the commitment of such institutions to protect the integrity of academic records. This is likely to enhance records keeping in such institutions.

Azamati and Adjei (2013) indicated that among tertiary institutions in Ghana teacher training colleges and public universities were more committed to ensuring credible academic records keeping than private universities, polytechnics and nursing colleges. It further stated that tertiary institutions adopt practices deemed convenient and effective for curbing irregularities in academic records

Administrative records management is pivotal to all tertiary institution and to every information with individuals playing major roles within such entities. The most important role is to help in the easy dissemination of information within the institution, to guarantee that the information is swiftly made accessible at the right time, right place and with a minimal cost. Heads of organizations should assign a member of staff (Records Manager) who is at a higher ranking level to ensure and guarantee that a proper records management systems are implemented and maintained (Kanzi, 2009).

\subsection{Positive Effects Derived from Administrative Records Management}

Shepherd (2010) stated that transparency and protection of citizens' rights in a democratic society can be expected only when proper records management is adhered to. They ensure the facilitation of citizens partaking in governance through the provision of information, digital interaction and electronically enabled services.

Records management according to Mnjama (2004) is beneficial to an organization as a major resource including; records themselves are organizational assets because they document organizational activities and are needed for audit trails, especially in establishing the content and context for their creation.

Stede et al (2006) report the growing evidence that effective records management and greater use of same deliver better organisational performance. Research has also shown that a functional records management system reduces the cost of administering an organization as well as good decision making.

Akotia (2003) and Ngulube (2005) have reported that 75 percent of information needed to make a decision in an organization is contained in the available records of the organization.

Tsabedze et al. (2010) as cited by Ajiboye et al. (2016) reported that a lack of proper documentation of files in which records are kept impede and slow the decision-making process of government officials of the 17 government ministries of Swaziland they investigated.

Atulomah (2012) indicated that roles played by the university administrators were significantly dependent on their records management practices.

\subsection{Records life Cycle}

International Management Trust (IMT) (1999) shows that records can only be managed effectively and efficiently if attention is given to their handling from the period/ time they are created until when they are disposed of or retained as archival records. The life cycle theory is that recorded information has a life similar to that of a biological organism, in that it is born, it lives, and it dies. Schellenberg (1956) as cited by Shepherd and Yao (2003) confirm the life cycle concept of records and indicated that the idea was developed in North America. In some narrow interpretations, these three stages are seen as the equivalent of current, semi-current and non-current (or archival) phase of a record. The records life cycle theory is equated to the records management activities of creation, maintenance and use, and disposal (IMT, 1999). Each of the phases has various elements associated with it and functional activities are performed within each element (Penn, et al, 1994).

Pen, et al (1994) however, argues that this division need not be overstressed. This is because the ultimate goal of the life cycle model is not to develop a set of ways in handling all the numerousdifficulties and conditions of records management, but to create a sound methodology for assessing situations so that the most suitable course of action can be taken in each case.

Shepherd and Yeo (2003) stated in disagreement to the two approaches. They were of the view that the two approaches are not incompatible. The protest is not to the life cycle concept itself, but to those manifestations of it that reflect an undeveloped view of records management or try to introduce excessive practical detail. Specific practice will vary, they 
contend, from one working context to another, but models based on the life cycle help to identify stages and actions within a records management programme, and thus provide a useful framework for planning, implementation and monitoring. Records management and archives administration constitute one field unified through the records life cycle concept.

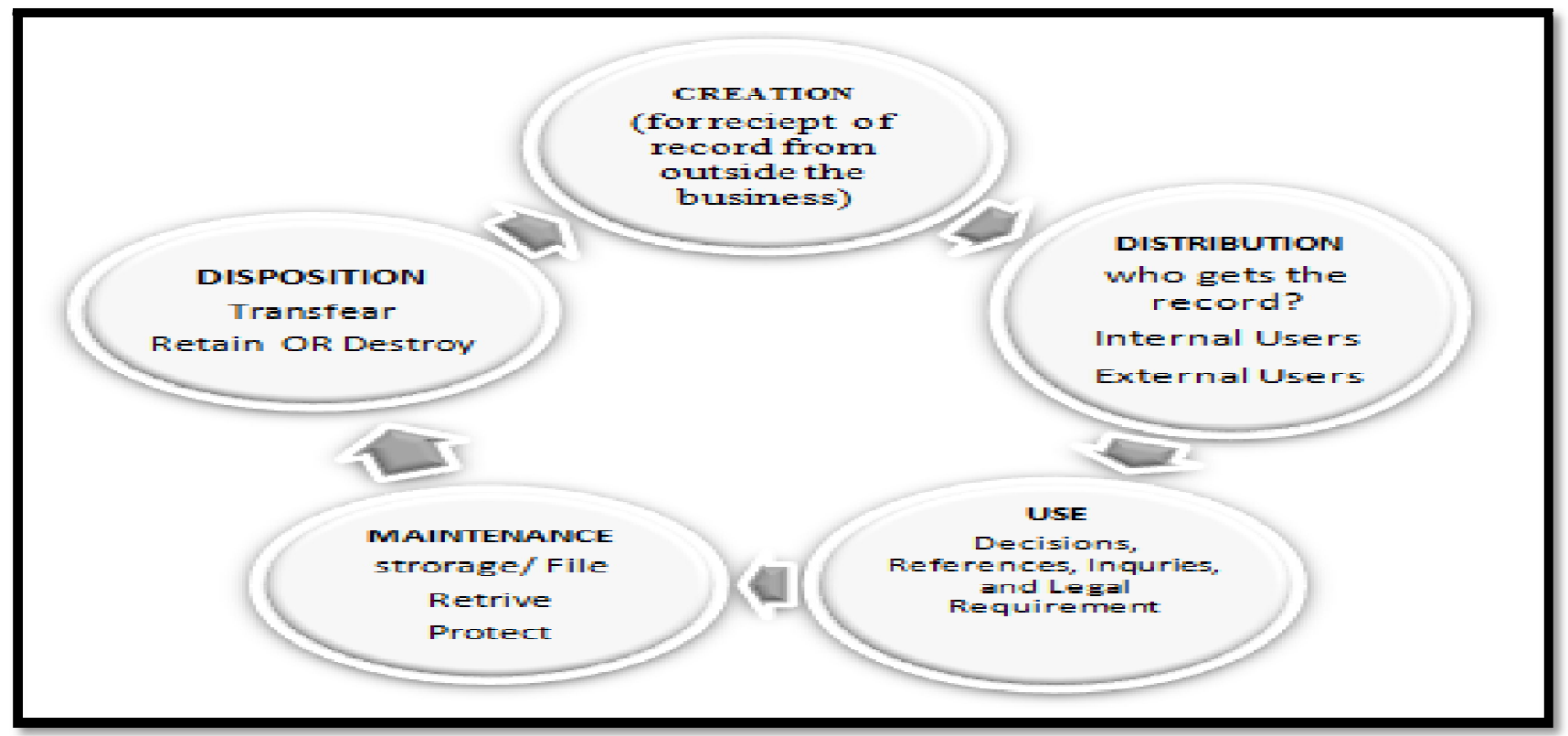

Figure1: Records and Information Life Cycle Source: (Read and Ginn, 2016)

\section{Methodology}

A descriptive research design was used in this study. The study population was comprised of Administrative staff, Records staff and Senior Management of TUs in Ghana. A stratified sampling technique was used to sample 50 respondents from the TUs. 10 respondents were selected from each Technical University. The sample institutions included the Kumasi Technical University, Sunyani Technical University, Takoradi Technical University, Accra Technical University and Tamale Technical University. Data were analyzed with SPSS version 17. Tables and Multiple Bar Charts were used to describe the data.

\subsection{Data Analysis and Discussion of Findings}

\begin{tabular}{|c|c|c|}
\hline Management Practices & Frequencies & Percentages (\%) \\
\hline \multicolumn{3}{|c|}{ Documents Storage } \\
\hline Manually & 10 & 20 \\
\hline Electronically & 3 & 6 \\
\hline Both Manually And Electronically & 37 & 74 \\
\hline Total & 50 & 100 \\
\hline \multicolumn{3}{|c|}{ Filing Period Of Documents } \\
\hline Every Day & 44 & 88 \\
\hline Every Week & 3 & 6 \\
\hline Every Month & 2 & 4 \\
\hline Every Three Months & 1 & 2 \\
\hline Total & 50 & 100 \\
\hline \multicolumn{3}{|c|}{ Type of Management System } \\
\hline Centralized & 13 & 26 \\
\hline Decentralized & 7 & 14 \\
\hline Both & 30 & 60 \\
\hline Total & 50 & 100 \\
\hline \multicolumn{3}{|c|}{ Monitoring And Controlling Management of Records Person } \\
\hline Records Officer/ Archivist & 11 & 22 \\
\hline Administrative Staff & 38 & 76 \\
\hline Other & 1 & 2 \\
\hline Total & 50 & 100 \\
\hline
\end{tabular}




\begin{tabular}{|c|c|c|}
\hline Management Practices & Frequencies & Percentages (\%) \\
\hline \multicolumn{3}{|c|}{ Stages Records Pass Through } \\
\hline Five & 12 & 24 \\
\hline Four & 13 & 26 \\
\hline Three & 22 & 44 \\
\hline Others & 3 & 6 \\
\hline Total & 50 & 100 \\
\hline
\end{tabular}

Table 1: Displayed the Assessment of Administrative Records of the TUs

Source: Field Work, 2017

Factors assessed include; storage of office documents, a period by which official documents are filled, types of records management system practice within the TUs, monitor and controller of records management and the stages records passed through in the TUs.

First and foremost, considering the storage of office documents, $10(20 \%)$ of the respondents indicated that, they were using manual system in storing their office documents, $3(6 \%)$ indicated that they were applying the electronic form of storing document and 37 (74\%) indicated that the two systems (i.e. electronic and manual) were being used to store records. This means that the storing of the document was much concentrated in the use of the two methods and only a few used only the electronic form of storage. This affirms Gregg (2013) which indicates that accessibility through hardcopy files only limits the search to a single location but having electronic format improves on the search for increased accessibility.

Furthermore, considering the period of filing documents it indicated that $44(88 \%)$ of the responses file documents daily, $3(6 \%)$ of the responses file documents weekly, 2 (4\%) of them indicated the filing was done monthly and only $1(2 \%)$ showed that it has been done quarterly. This implies that the TU's made use of the daily filing of records more than the others and few files the documents quarterly.

Moreover, the responses from the respondents indicated the type of management system used for administrative records as centralized, decentralized and the use of both. Those that used the centralized system were 13 (26\%), those that used the decentralized system were $7(14 \%)$ and those that used the two stated were $30(60 \%)$. This means that the TUs made use of the two systems and only little pay attention to the decentralized system.

The next thing considered was the monitor and controller of the management of administrative records. The responses indicated $11(22 \%)$ managed and controlled records by the records manager, $38(76 \%)$ were managed by the administrative staff and only $1(2 \%)$ indicated that records were controlled and managed by both records manager and administrative staff. This implies that most of the administrative records were much monitored and controlled by the Administrative staff more than Records Managers.

The final assessment of administrative records management was the stages records passed through within the TUs. The responses indicated that, 12 (24\%) of the administrative records passed through 5 stages in the TUs, $13(26 \%)$ of them passed through four stages in the TUs, for those that passed through 3 stages were $22(44 \%)$ and the other stages that had not been included were $3(6 \%)$. This means that the majority of the records of the TUs passed through 3 stages which are not in line with the records life cycle which has five stages.

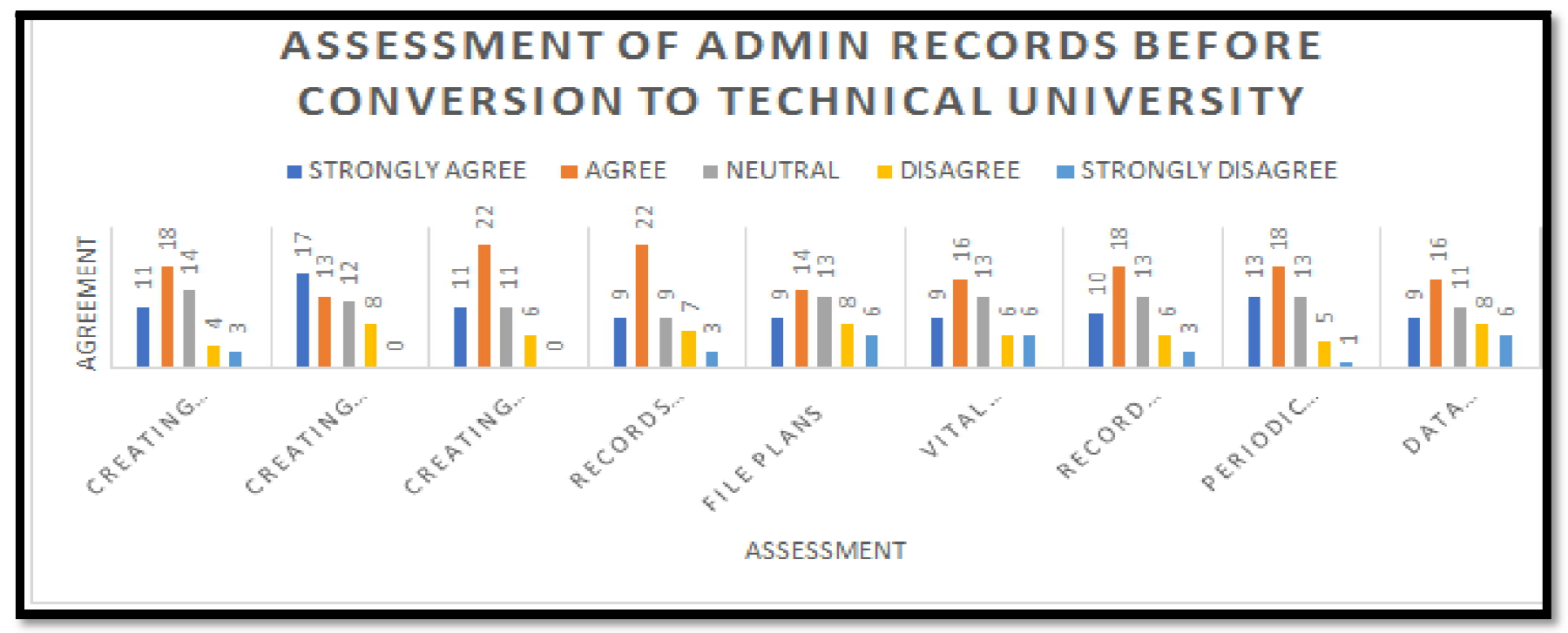

Figure 2: Multiple Bar Charts Showing the Assessment of Administrative Records with Their Various Level of Agreement Source: Fieldwork, 2017 
Figure 2 displayed the assessment of the administrative records with the level of agreement of the respondents at the Polytechnics before the conversion to TUs. The ways of assessment included; policies and procedures for the creation and storage of records in paper format, policies and procedures for the creation and storage of records in electronic format, policies and procedures for the creation and storage of records in both paper and electronic format, thoroughly documented policies that list records categories and expected retention time, organized file plan, vital records program, periodically organized to ensure quality records were kept, periodic audit to ensure that enforcement vehicle that assesses the clarity of procedures and adequately addresses data privacy and security issues with their respective level of agreement as strongly agree, agree, neutral, disagree and strongly disagree.

The responses indicated that the Polytechnic policies and procedure for the creation and storage of records in paper format showed $29(58 \%)$ of them agreed to that fact, $14(28 \%)$ were not certain and $7(14 \%)$ disagree to that fact. For the policies and procedures used in the creation and storage of records in electronic format, $30(60 \%)$ agreed, 12 (24\%) were not certain and $8(16 \%)$ disagree. Policies and procedures for creating and storing records in both electronic and paper format, $33(66 \%)$ were in agreement, $11(22 \%)$ were not sure and $6(12 \%)$ were not in agreement. Taken the thoroughly documented policies that list records categories and expected retention time, 31(62\%) were in agreement, $9(18 \%)$ were not sure and 10 (20\%) disagreed. For the organizational file plan, 23 (46\%) were in agreement, $13(26 \%)$ were not sure and $14(28 \%)$ were not in agreement. The use of vital records program that serves as a back-up in case of disaster, 25(50\%) was in agreement, 13 (26\%) were not sure and $12(24 \%)$ disagree. To continue with the periodically organized to ensure quality records were kept indicated that, $28(56 \%)$ were in agreement, 13(26\%) were not sure and 9(18\%) disagree. The periodic audit indicated that $31(62 \%)$ were in agreement, $13(26 \%)$ were not sure and 6(12\%) disagree and finally, 25(50\%) were in agreement, 11(22\%) were not sure and $14(28 \%)$ did not agree.

The responses from the respondents indicated that, the most emphasized assessment of records by the then Polytechnics before the conversion to the TUs was the policies and procedures for the creation and storage of records in both paper and electronic format, followed by the periodic audit that provides an enforcement vehicle that assesses the clarity of procedures, then to thoroughly documented policy that list records categories and expected retention time, the fourth and fifth assessment of administrative records were policies and procedures used for the creation and storage of records electronic format and paper format respectively. The sixth was management periodically organizes to ensure that quality records were kept. The least assessment of administrative records was the organizational file plan that lists primary types of functional units so that information can be located without depending on any specific employee.

This implies that, before conversion to TUs, attention was much concentrated on that policies and systems used for the creation and storage of records in both paper and electronic format. The statement affirms with Uwaifo (2004) who indicatedthatby and large, some level of confidentiality, proper maintenance, security of content and context should be the guiding principle for sound records management.

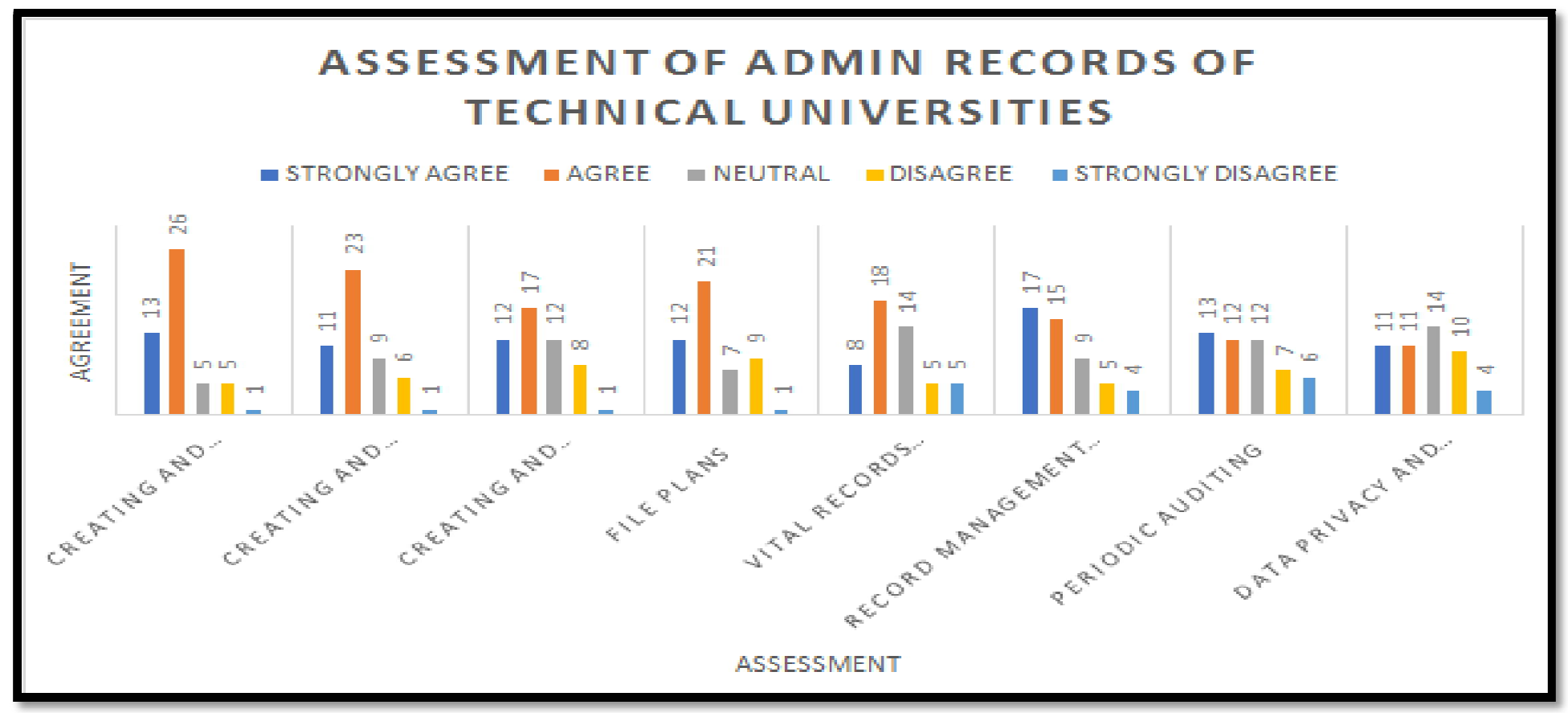

Figure 3: Multiple Bar Charts Showing the Assessment of Administrative Records of the TUs and

Their Varying Level of Agreement

Source: Fieldwork, 2017 
Figure 3 displayed the assessment of the administrative records with the level of agreement of the respondents at the TUs. The ways of assessment include; policies and procedures for the creation and storage of records in manual format, policies and procedures for the creation and storage of records in soft format, policies and procedures for the creation and storage of records in both manual and soft formats, organized file plan, vital records program, periodically organized to ensure quality records were kept, periodic audit to ensure that enforcement vehicle that assesses the clarity of procedures and adequately addresses data privacy and security issues with their respective level of agreement as strongly agree, agree, neutral, disagree and strongly disagree.

From the responses above, 39(78\%) agreed, $5(10 \%)$ were not sure and $6(12 \%)$ of the respondents disagree to the policies and procedure used in the creation and storage of records in manual format. Also, 34(68\%) agreed, 9(18\%) were not sure and $7(14 \%)$ of the respondents disagreed to the policies and procedures used for the creation and storage of records in soft format. Talking about the use of both manual and soft format, 29(58\%) were in agreement, 12(24\%) were not sure and $9(18 \%)$ disagreed. To talk of the organizational file plan that compiles primary types of functional units, 33(66\%) were in agreement, 7(14\%) were not sure and $10(20 \%)$ disagreed. To continue with the TUs vital records program that serves as a back-up in case of emergency, 26(52\%) agreed, 14(28\%) were not sure and 10(20\%) disagreed. Also, 32(64\%) agreed, $9(18 \%)$ were not sure and $9(18 \%)$ disagreed that there is a periodic audit that provided an enforcement vehicle of procedures. Finally, the TU's adequately addresses the issue of data privacy and security showed 25(50\%) agreement, $12(24 \%)$ not sure and $13(26 \%)$ disagreement.

What the TUs do assess most was procedures and policies used for the creation and storage of records in manual format, policies and procedure used in the creation and storage of records in soft format and then moved to the organization of file plan that list of primary types of functional units. The periodic audits as an enforcement vehicle that assesses the clarity of procedure were less used and then data privacy and security issues were the least used. It was observed from the responses that, policies and procedures for the creation and storage of records in the two (manual and soft) format were much concentrated on but data privacy and security and the periodic audit was not given much attention to by the Universities. This means that there was no significant change between before and after the conversion of the Polytechnics into TUs. However, it was observed from fig 4.0 and fig 4.1 that, all were well assessed but there existed a bit change after the conversion to the TUs. After the conversion to the TUs, there is an improvement of the following areas; policies and procedures used in the creation and storage of records in manual format, policies and procedures used in the creation and storage of records in soft format, organizational file plan that compile primary types by functional units in order to locate information/ documents without relying on any specific employee and also adequately addressing data privacy and security issues was less concentrated on.

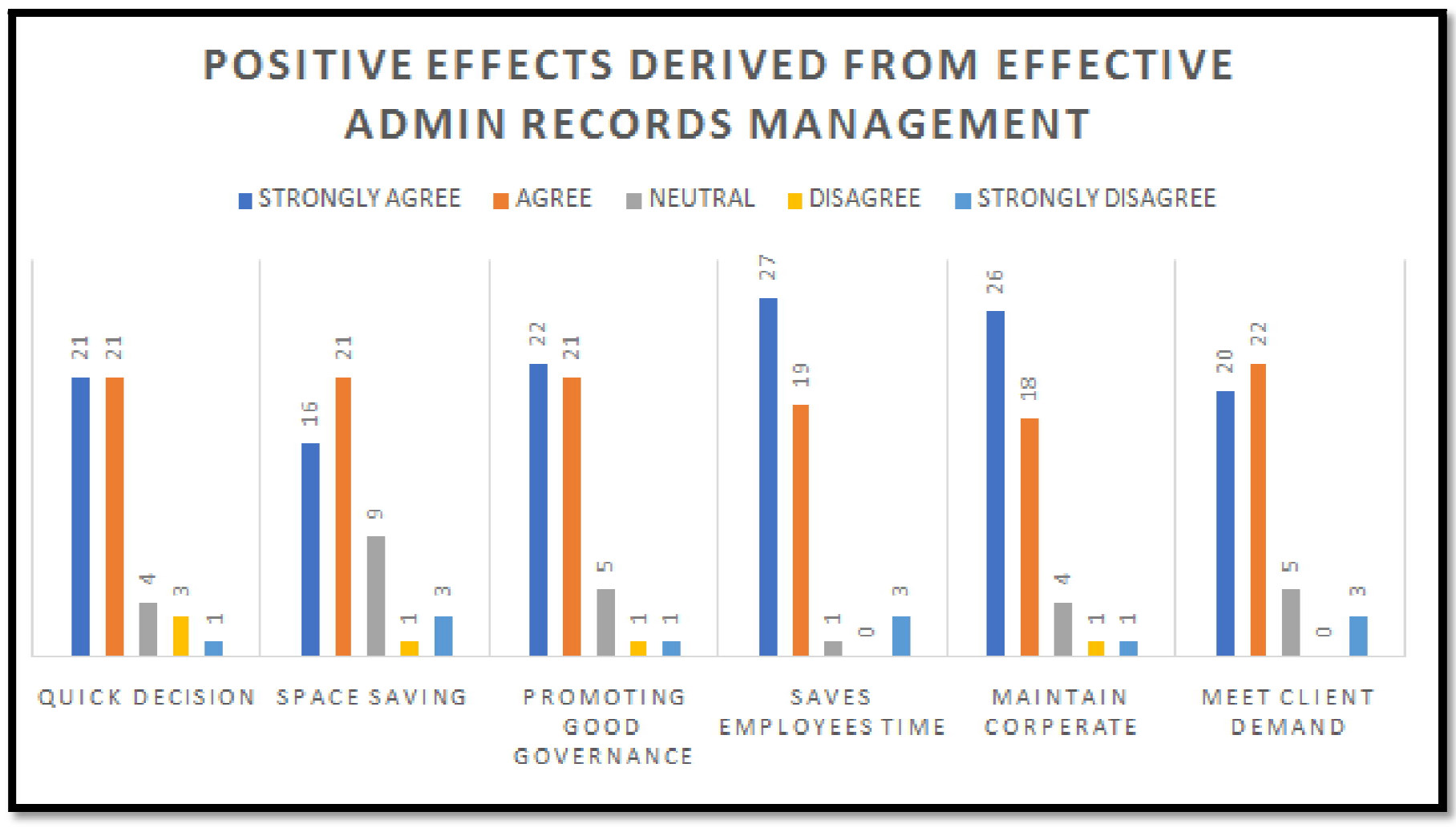

Figure 4: Multiple Bar Charts Showing the Positive Effects Derived from Effective Records Management Source: Fieldwork, 2017 
Figure 4 above displayed the positive effects that were derived from effective administrative records management. Some of the positive effects discussed were quick decision making, space saving, promotion of good governance, saving of employees' time, maintenance of corporate and institutional memory, and meeting of client demand with their various level of agreements as strongly agree, agree, neutral, disagree and strongly disagree.

The results from the respondents indicated that $42(84 \%)$ agreed to quick decision making as a positive effect, 4(8\%) were not sure and $4(8 \%)$ did not agree that there was a quick decision making at the TUs. This is in agreement with Hebert (1998) as cited by Adu (2014) who indicated that records help in making the right decisions, demonstrating compliance, documenting the history of the University and more importantly enabling the execution of the institutions' jobs. The positive effect as space saving also indicated that, 37(74\%) of the respondents were in agreement, 9(18) were not sure and 4(8\%) disagreed that there was space saving as a positive effect derived from effective administrative records management which affirms an assertion by Shepherd and Yao (2003) indicating that records management, in theory, and practice accentuate that it is essential to use appraisal technique to support decisions about retention that is the duration given to each record once it is created until its final disposition (destruction or permanent preservation). This shows that proper record management prevents a situation in which ephemera records are kept for a lengthy period of time which results in congestion of the limited office spaces. Furthermore, $43(86 \%)$ of the respondents were in agreement that effective administrative record management promotes good governance, 5(10\%) were not sure and 2(4\%) disagree. This response is in agreement with McLeod and Childs (2007), who indicated that good records management help in the demonstration of accountable governance, clarity of transactions and corporate governance and it is means of information indicating open government and freedom of information in the context of the ordinary citizens.

To talk of the saving employees time, $46(92 \%)$ were in agreement, $1(2 \%)$ was not sure and $3(6 \%)$ disagree. For the maintaining corporate and institutional memory within the TUs, 44(88\%) agree, 4(8\%) were not sure and 2(4\%) disagreed. The finalpositive effect to be considered was meet client demand showed $42(84 \%)$ agreement, 5(10\%) were not sure and $3(6 \%)$ disagreed.

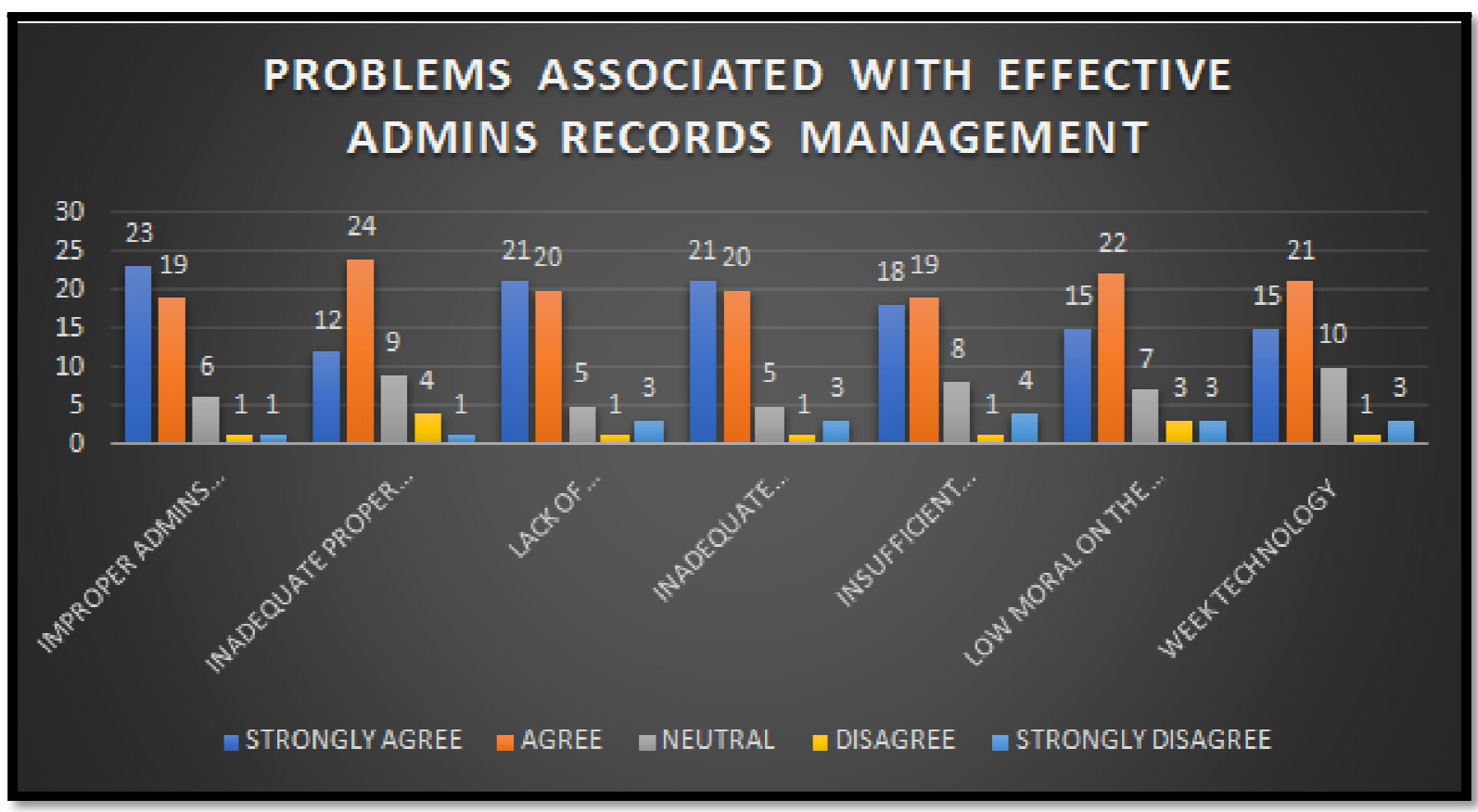

Figure 5: Challenges Associated with Effective Administrative Management and the Level of Agreement of the TUs Source: Field Work, 2017

Figure 5 displayed the challenges that were associated with effective administrative records management with their corresponding level of agreement. The challenges were retrieving office document due to improper administrative records management, inadequate proper security for records, lack of professionally trained Records Officers/Archivist, inadequate resources to facilitate proper management of records, insufficient resources to facilitate administration records management, low morale on the part of records keepers and week technological support and the administrative of the TUs.

Among the responses from the respondents, 42(84\%) were in agreement, $6(12 \%)$ and $2(4 \%)$ disagreed in the challenge in retrieving office documents, as a result of improper administrative records management. For the inadequate proper security, 36(72\%) agreed that is a challenge, $9(18 \%)$ were not sure and 5(10\%) did not agree that it is a problem. Also, in the case of lack of professionally trained Records Officers/ Archivist, 41(82\%) were in agreement, 5(10\%) were not sure and $4(8 \%)$ disagreed. Inadequate resources record to facilitate proper management of records, 41(82\%) were in agreement, 
$5(10 \%)$ were not sure and $4(8 \%)$ did not agree. The challenge of insufficient resources to facilitate administrative records management, 37(74\%) agreed, 8(16\%) were not sure and 5(10\%) disagreed. Low morale on the part of records keepers due to poor remuneration, 37(74\%) were in agreement, 7(14\%) were not sure and 6(12\%) disagreed. Finally, week technology as a challenge, 36(72\%) agreed, 10(20\%) were not sure and 4(8\%) disagreed.

Among the stated the challenges, the challenge of retrieving office documents due improper administrative records management was the major challenge associated with administrative records management, the next challenge was lack of professionally trained Records Officers/Archivist and resources to facilitate proper management of records, the third challenge observed was insufficient resources to facilitate administrative records management and the slightest challenge was the weak technology. There was an indication that improper administrative records management is the major challenge since it affects the retrieval of office documents and the minimal challenge was weak technological support. This means that the level of technology was not high but its effect was low by the TUs.

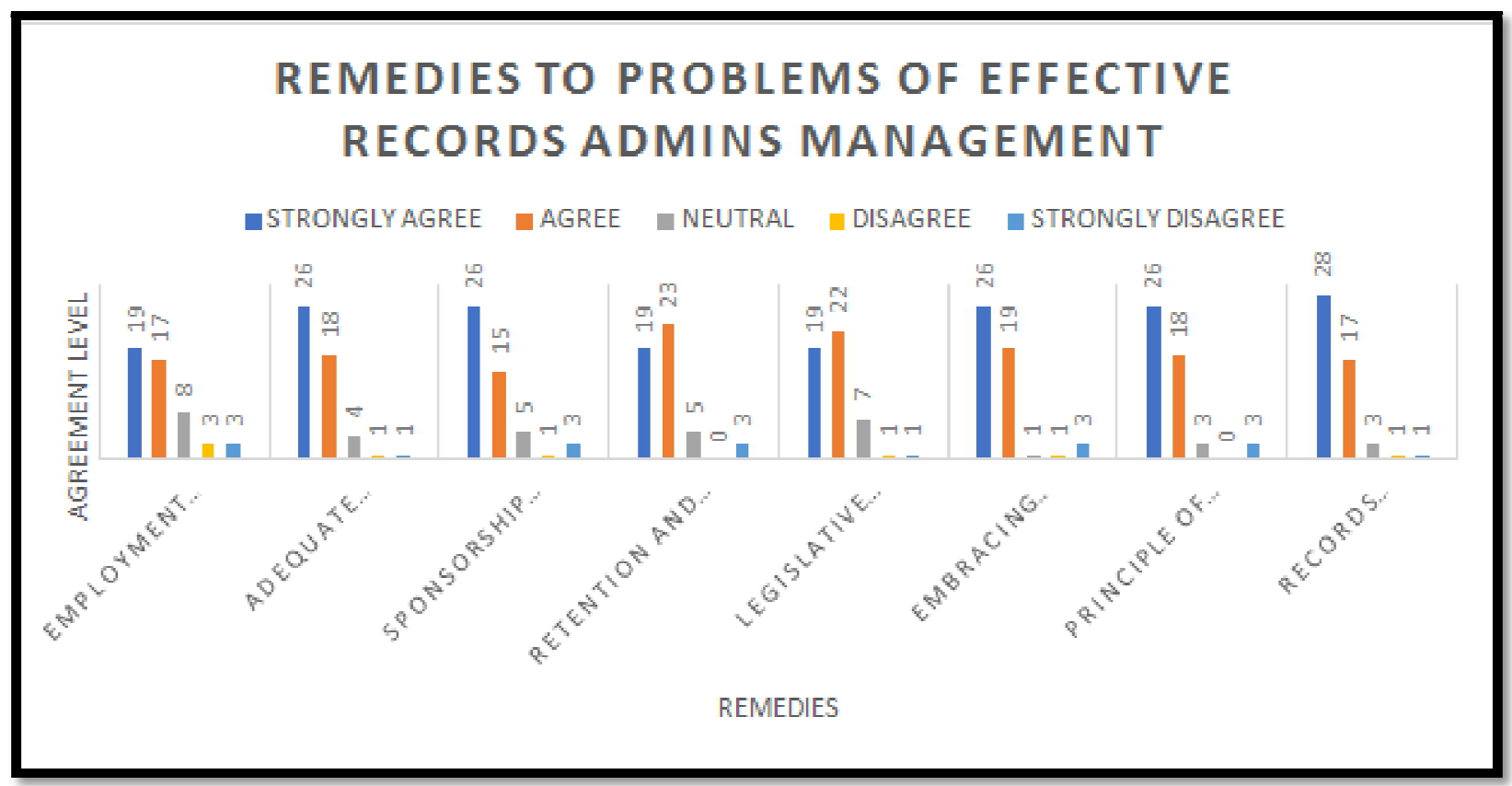

Figure 6: Multiple Bar Charts Showing the Remedies to Challenges Associated with Effective Administrative Records Source: Field Work, 2017

Figure 6 displayed the remedies to challenges associated with effective records management. There were eight remedies that were considered to address challenges affecting administration records management. These include; employment of Records Officer/ Archivist, adequate training for all administration staff on records management, sponsor of unskilled staff for higher education, implementation of retention and disposal schedules, adherence to legislative frameworks on data protection, embracing emerging technologies to improve on administration records, enforcing the principle of accountability and finally, administrative record management factored into TUs strategic plan with their respective level of agreements.

Of the responses from the respondents, 36(72\%) agreed that the TUs employed Records Officer/ Archivist, 8(16\%) were not sure and $6(12 \%)$ disagreed. The given of adequate training to administration staff on records management, 44(88\%) were in agreement, $4(8 \%)$ were not sure and $2(4 \%)$ disagree. Of the responses from the respondents indicated that for the sponsorship for higher academic and professional qualification, 41(82\%) were in agreement, 5(10\%) were not and 4(8\%) disagreed. For the implementation of retention and disposal schedules as a remedy to the stated challenges, $42(84 \%)$ agreed, $5(10 \%)$ were not sure and 3(6\%) disagreed. Again, adherence to legislative frameworks/ instruments on data protection and records management, $41(82 \%)$ were in agreement, $7(14 \%)$ were not sure and 2(4\%) disagree. Moreover, the embracement of emerging technologies for the improvement of record management, 45(90\%) agreed, 2(4\%) were not sure and 3(6\%) disagreed. To add to the aforementioned once was the enforcement of principles of accountability, 44(88\%) were in agreement, 3(6\%) were not sure and 3(6\%) disagreed. And finally, the factoring record management plan into TUs strategic plan, 45(90\%) were in agreement, 3(6\%) were not sure and 2(4\%) did not agree.

The responses showed that all the above factors were remedies applied to the challenges associated with effective administrative records management.

However, adequate training for administration staff on records management, embracing emerging technologies, the principle of accountability as enforcement and factoring of TUs strategic plans were the major remedies to the challenges. 
Also, employment of Records Officer/ Archivist, sponsorship to higher education, implementation of retention and disposal schedules and adherence to legislative frameworks were the minor remedies.

\section{Conclusion and Recommendations}

Administrative Records Management role must be integrated into the strategic planning initiatives of TUs. Most importantly, Top Management must accept that administrative records management role as part of performance targets set in the TUs. The following is therefore recommended by the researchers:

- All TUs should have internal policies for regulating administrative records keeping systems. These policies should make it obligatory to produce a restricted number of copies of sensitive documents in different formats to be kept under stringent security. This will help to reduce the rate of data loss and delays in retrieving records during power outages and hard drive crashes.

- Adequate measures should be adopted to ensure that retrieval of administrative records is made with ease. These measures may include the adoption of electronic record keeping which must stay up-to-date on current data base applications, software and data security issues so as to safeguard the sanctity of records.

- $\quad$ TUs should likewise secure database applications and administrative records keeping the software for their record keepers.

- Administrative Staff should be given adequate training on regular basis on administrative records management to ensure that they are able to undertake the full responsibilities of overseeing the welfare of the Technical University's records.

- The study showed the lack of a professionally trained Records Officers/ Archivist even though it was one of the least to be considered as remedies for administrative records management. It is regrettable that most TUs have no Records Officers/ Archivist on their Campuses. The TUs needs to appoint professionally trained Records Officers/ Archivist who will be responsible to compile, implement, maintain and utilize all approved filing systems, legislation and accordingly filing documents to follow the approved systems.

- Also, to ensure the improvement of institution's administrative records management practices, the Records Officers/Archivist should be dedicated only to the records management function. TUs Management should appoint separate Assistant Records Officers for all functional offices/ units of their University's. They should be charged with the responsibility of ensuring sound records management within their respective divisions. Such Assistant Records Officers should remain accountable to the Head of Records / Archivist of the entire Technical University.

\section{References}

i. Adu, F. (2014). Assessment of Records Management Practices among the Administrative Staff of University ofEducation, Winneba-Kumasi (UEW-K) and Mampong (UEW-M) Campuses (Doctoral Dissertation).

ii. Akotia, P. (2003). Public Sector Records Systems in Ghana: Some Lessons in Development Management. African Journal of Library, Archives and Information Science, 13(2), 107-117.

iii. Ajiboye, B. A., Alegbeleye, O. G., Okonedo, S., Oyedipe, W. J., Emmanuel, S. O., \&Alawiye, M. K. (2016). Records Management Practices in The Administration of The Church of Nigeria (Anglican Communion). Records Management Journal, 26(1), 4-20.

iv. Atulomah, B. C. (2012). Records management practice and decision-making among university administrators in Nigeria (Doctoral dissertation, Ph. D. Thesis. LARIS. University of Ibadan, 215p).

v. Azameti, M. S. K., \& Adjei, E. (2013). Academic Assessment of Students Work and Quality Assurance in Tertiary Institutions: A Conceptual Framework. International Journal of Educational Foundation and Management, 1(2), 153165.

vi. Bailey, T., Cloete, N., \& Pillay, P. (2011). Universities and Economic Development in Africa: Case Study-Ghana and University of Ghana; Accra; University of Ghana

vii. Bearman, D. (1994). Electronic evidence: strategies for managing records in contemporary Organizations. Archives \& Museum Informatics. Pittsburgh

viii. Brooks, C. (2007). Record Management 101: Understanding is the First Step to Knocking out PoorRecord Management. Doc Magazine, 21 (3), 16. Retrieved, February 2018 from http:/ / proquest.umi.com

ix. Cox, R.J. (2001). Managing Records as Evidence Information. London Westport. Duose J. I. (2009). Record-keeping and Accountability:Ghana@50inRetrospecthttp:/ / www.ghanaweb.com/ GhanaHomePage/ NewsArchive/ artikel.php?ID=1 68079 Retrieved January 2018

x. Duranti, L. (2010). Concepts and Principles for the Management of Electronic Records, Or Records Management Theory is Archival Diplomatics. Records Management Journal, 20(1), 78-95.

xi. Dzandu, S. (2009). Record-Keeping: Key to Good Governance Available: http://www. modernghana.com/ news/ 208439/ 1/ record-keeping-key-to-goodgovernance.html.Retrieved February, 2018.

xii. Dzandu S. (2009). Record-keeping and Accountability: Ghana@50 in Retrospect. http:/ / www.ghanaweb.com/ GhanaHomePage/ NewsArchive/ artikel.php?ID=168079Retrieved Feburary,2018 
xiii. Edward, S., \& McLeod, J. (2004). Is the Freedom of Information Act Driving Records

xiv. Management in Further Education Colleges? Records Management Journal, 14(1), 40-50.

xv. Gregg B. (2013). Document Imaging and Electronic Content Management. Key Challenges of Paper-based Information. Canon Business Process Services, INC

xvi. International Organization for Standardization (ISO), (2001). ISO 15489-1 Information and documentation-records management-part 1 general. ISO, Geneva.

xvii. International Management Trust (1999). Managing Archives: Managing Public sector Records Management Handbook. London: Aldershort.

xviii. International Records Management Trust (IRMT), (2008). Integrating Records Management in ICT System: Good Practice Indicator, IRMT, London.

xix. Kanzi, N. (2009). An Investigation of The Role of Records Management with Specific Reference to Amathole District Municipality. Master's Thesis, Nelson Mandela Metropolitan University

xx. Kenosi, L. S., \& Mosweu, O. (2018). A Framework for a Good Recordkeeping System. InHandbook of Research on Heritage Management and Preservation (pp. 213-234). IGI Global.

xxi. McKemmish, S. (2001). Placing Records Continuum Theory and Practice. Archival Science, 1(4), 333-359.

xxii. McLeod, J., \& Childs, S. (2007). Consulting Records Management Oracles-a Delphi in practice. Archival Science, 7(2), 147-166.

xxiii. Ministry of Education (M.O.E) (2014).Report of the Technical Committee on Conversion of the Polytechnics in Ghana to Technical Universities, Accra: M.O.E.

xxiv. Mnjama, N. (2004). Records and Information: the Neglected Resource. ESARBICA Journal23:44-59.

xxv. Mnjama, N.M. (2002). Managing University Records. ESARBICA Journal: Journal of the Eastern and Southern Africa Regional Branch of the International Council on Archives21: 32-4

xxvi. Ngoepe, M. (2004, September). Accountability, Transparency and Good Governance: The National Archives and Records Service of South Africa's Role in Helping Government to Better Service Delivery to the South Africans. In Liasa's 7th Annual Conference in Polokwane, South Africa (Vol. 27)

xxvii. Ngulube, P. (2005). Managing records at higher education institutions: a case study of the University of KwaZuluNatal, Pietermaritzburg Campus. South African Journal of Information Management, 7(1)

xxviii. Ngulube, P. (2004). Fostering Accountability and Justice: Opportunities for Records Managers in Changing Societies. ESARBICA Journal, 23, 23

xxix. Penn, I., Pennix, G. and Coulson, J. (1994). Records Management Handbook, 2nd Edition.

xxx. Aldershot: Gower

xxxi. Read-Smith, J., \& Ginn, M. L. (2016). Records Management. Boston; Cengage Learning. Shepherd, E. (2010) Archival Science. Encyclopedia of Library and Information Sciences 3rded. 1(1):179-191

xxxii. Shepherd, E. (2006). Why are Records in the Public Sector Organizational Assets? Records Management Journal, 16(1), 6-12.

xxxiii. Shepherd, E. \& Yeo, G. (2003). Managing Records: a Handbook for Principles and Practices, Facet Publishing, London.

xxxiv. Stede, W. A. V. D., Chow, C. W., \& Lin, T. W. (2006). Strategy, Choice of Performance Measures and Performance. BehaviouralResearch in Accounting, 18(1), 185-205.

xxxv. Uwaifo S. O. (2004). Management Use of Records at Delta State University, Abraka, Nigeria.

xxxvi. Wamukoya, J. (2000). Records and Archives as A Basis for Good Government: Implications and Challenges for Records Managers and Archivists in Africa. Records Management Journal, 10(1), 23-33.

xxxvii. Wema, E. (2003). Problems of managing semi-active records in institutions of higher learning: the Case of University of Dar Es Salaam. University of Dar es Salaam Library Journal,5(1), 46-56. 